\title{
25 anos de Ciência \& Saúde Coletiva: trajetória e perspectivas
}

\section{5 years of Ciência \& Saúde Coletiva: trajectory and prospects}

Neyson Pinheiro Freire (http://orcid.org/0000-0002-9038-9974) ${ }^{1}$

${ }^{1}$ Editor de Comunicação e Divulgação Científica, Revista Ciência \& Saúde Coletiva, Associação Brasileira de Saúde Coletiva. Av. Brasil 4036, sala 700,

Manguinhos. 21040-361 Rio de Janeiro RJ Brasil. neysonfreire@gmail.com

\begin{abstract}
The trajectory of the Journal Ciência \& Saúde Coletiva reveals a growing impact and credibility of the publication, which expanded its periodicity and consolidated itself as a benchmark in the discussion, implementation, and memory of Collective Health public policies and trends. Universal access and dissemination in digital media increased its outreach, both in search engines and social networks, bringing scientific knowledge to a broader audience.
\end{abstract}

Key words Health Communication, Collective Health, Scientific Dissemination Publications
Resumo A trajetória da Revista Ciência \& Saúde Coletiva revela um crescente impacto e credibilidade da publicação, que expandiu sua periodicidade e se consolidou como referência na discussão, implementação e memória das políticas públicas e tendências na área de Saúde Coletiva. A opção pelo acesso universal e a difusão em meios digitais contribuiu para o aumento do alcance, tanto em mecanismo de busca quanto em redes sociais trazendo conhecimento científico a um público ampliado.

Palavras-chave Comunicação em Saúde, Saúde Coletiva, Publicações de Divulgação Científica 
Se pudesse sintetizar a trajetória de 25 anos da Revista Ciência \& Saúde Coletiva em uma palavra seria "credibilidade". Desde que nasceu, em 1996, a publicação vem fazendo jus ao que se propôs em seu primeiro editorial: "ser um instrumento de divulgação e reflexão crítica da história e da memória do campo, de análise do 'estado da arte' das disciplinas que o compõem, das tendências e perspectivas do pensamento das teorias e das práticas da Saúde Coletiva...." Não por acaso, o periódico figura hoje entre os três mais importantes do universo científico ligado aos temas de saúde coletiva ${ }^{1}$.

Em um quarto de século, a revista tem acompanhado a implementação do Sistema Único de Saúde, a expansão da atenção básica, retorno de doenças infectocontagiosas controladas, o desafio da equidade e a pandemia de Covid-19, sem precedentes no curso das últimas gerações. A efeméride nos remete à comemoração das Bodas de Prata dos casais. O material escolhido para simbolizar a data é a prata, por ser um metal precioso, maleável e duradouro. $\mathrm{Na}$ era do sucesso instantâneo, das relações líquidas e acordos voláteis, uma publicação que alcança a marca dos 25 anos merece, no mínimo, uma reflexão sobre a razão de sua longevidade.

A revista nasceu em um momento complexo, marcado pelo início da exploração comercial da internet no Brasil. Na virada do século, o rápido avanço das publicações digitais levou à crença de que as publicações impressas estavam fadadas a se tornar obsoletas. A diretoria da Associação Brasileira de Saúde Coletiva (Abrasco), contudo, decidiu bancar a revista, considerando que a Associação tinha crescido o suficiente para ter um veículo próprio, que desse visibilidade à abundante produção científica da área e pudesse subsidiar cientificamente a construção do SUS.

De dois números anuais, a revista logo passou para quatro, depois para seis e, em 2011, começou a ser publicada mensalmente. O periódico foi ganhando cada vez mais consistência e respeito no meio científico, com um número respeitável de publicações. A pontualidade na divulgação, a qualidade e a relevância de seus artigos, que atualmente somam mais de 3.500/ano, respondem pela sua indexação em 23 bases de dados nacionais e internacionais. Entre as que oferecem maior visibilidade, destacam-se SciELO, Medline, ISI/Thomson e Scopus.

A partir do primeiro exemplar lançado, Ciência \& Saúde Coletiva cumpre os requisitos de normalização para publicação científica, seguindo as regras da Convenção de Vancouver, utili- zadas nas áreas de medicina e saúde pública. Sua singularidade, quando comparada aos outros periódicos da área é ser temática. Nesse contexto, consegue diversificar os conteúdos, publicando artigos de temas livres, de revisão ou de opinião, além de entrevistas, cartas e resenhas.

No ranking do Google Acadêmico (ou Google Scholar, em inglês), Ciência \& Saúde Coletiva é a número um dentre todos os periódicos científicos brasileiros ${ }^{2}$. Em setembro de 2019, a revista recebeu o prêmio internacional Research Excellence Awards Brazil, concedido pelo Web of Science Group, do Grupo Clarivate Analytics. A iniciativa reconheceu o bom desempenho da pesquisa brasileira, e a revista foi contemplada na categoria Prêmio Scielo Citation Index ${ }^{3}$.

O periódico ocupa também o terceiro lugar quanto ao fator de impacto medido pelo JCR, entre as 10 principais revistas nacionais da área de saúde pública ${ }^{4}$. É notável o seu compromisso com pesquisas e estudos de divulgação científica e a preservação do patrimônio documental e físico desses temas. Os prêmios são indicadores de que a semente plantada lá atrás deu frutos e segue se multiplicando, sem perder a consistência ou abrir mão das bandeiras nas quais acredita.

O posicionamento da revista é um dos pilares do seu sucesso. É uma revista que acredita na igualdade de oportunidades, ao universalizar o conhecimento científico, sempre fomentando o debate e jogando luz em temas decisivos para o desenvolvimento da área. Muito do que se pensou e se refletiu em saúde coletiva no Brasil e no mundo, nas últimas duas décadas, tem a ver com o que a revista publicou nesses 25 anos.

A pluralidade do conteúdo também merece destaque. Nesses 25 anos a revista teve edições com temas como "Qualidade de Vida e Saúde" (janeiro, 2000); "Humanização e Cuidados em Saúde" (março, 2005); "Saúde dos Trabalhadores: velhas e novas questões" (abril, 2005); "O SUS na prática: avanços e limites" (fevereiro, 2007); “Genética e Saúde Pública" (janeiro, 2002).

Alguns temas foram tratados de forma pioneira pela revista, abrindo caminho de discussões para novas políticas, como é o caso da "Saúde do Homem" (janeiro, 2005). A revista não furtou em trazer na capa temas considerados tabus, como "Aborto: um relevante tema interditado" (julho, 2012) e "Suicídio de Idosos no Brasil" (agosto, 2012). O periódico sempre buscou novos ângulos para velhas questões como violência, saúde dos trabalhadores, obesidade, alcoolismo, deficiência e saúde mental, acesso a medicamentos etc., cumprindo sua missão de propor e influenciar 
políticas de saúde, avaliação de políticas e serviços e financiamento do setor.

No ano de 2020, marcado pela pandemia da Covid-19, a revista lançou duas edições temáticas: Covid-19: a pandemia que revirou o mundo (Suplemento 1 - Junho/2020) e O que a Covid-19 revela e esconde (Suplemento 2 - Outubro/2020), facilitando o acesso à literatura relevante para a pesquisa sobre Covid-19. Notícias falsas mais disseminadas nas redes sociais brasileiras durante a pandemia foram objeto de levantamento em artigo intitulado "Fato ou Fake? Uma análise da desinformação frente à pandemia da Covid-19 no Brasil"s.

Sempre se atualizando, a revista não demorou a investir no digital. Além do alcance no Google Scholar, vem popularizando o conhecimento científico para um público ampliado nas redes sociais. Presente no Facebook, Instagram e Twitter, a Revista Ciência \& Saúde Coletiva permite o acesso a todo o seu conteúdo, atendendo a um de seus grandes princípios: popularizar a produção científica, facilitando o acesso a ela.

A popularização do acesso às informações é uma das bandeiras da revista, desde seu nascimento, ao proporcionar o "acesso aberto" ao conteúdo integral. Todos os leitores têm acesso livre e gratuito aos textos, em PDF, que podem ser baixados no Portal SciELO (www.scielo.org) e em sua home page (www.cienciaesaudecoletiva. com.br), clicando em edições.

Nas redes sociais, as métricas trazem boas notícias. Uma análise das publicações de setembro de 2019 a agosto de 2020 mostra que, no Facebook, até o final de agosto, foram registradas quase 600 mil impressões de publicações da revista, em uma média de 49 mil impressões por mês (Gráfico 1).

Com 6 mil seguidores no Facebook, a base de usuários vem crescendo em uma média de 84 novas curtidas da página/mês. Uma das publicações que mais gerou engajamento foi uma postagem de aniversário do SUS, em 19 de setembro de 2019. O post alcançou organicamente mais de 100 mil usuários, resultando no ganho de 500 seguidores em apenas um dia.

Já a publicação do artigo "A pandemia de Covid-19 para além das Ciências da Saúde", sobre os fundamentos histórico-sociais da pandemia, alcançou mais de 7 mil usuários. Foi a que mais trouxe alcance no período, sem impulsionamento pago (Figura 1). Os dois exemplos sugerem que efemérides e atualidades têm potencial para gerar engajamento e compartilhamento e podem ser trabalhados nesse sentido.
No Instagram, a edição de janeiro de 2020, sobre Sistemas de Saúde e Trabalho: Desafios da Enfermagem foi a mais curtida, com 176 likes e 33.099 de alcance (Figura 2). É uma rede social relevante, em que a revista tem investido na direção certa, para aumentar o número de seguidores, que até agosto somavam pouco mais de 2,6 mil. No Instagram, as postagens de Dicas de saúde estão entre as que mais têm gerado engajamento.

Diferentemente das demais redes, o Twitter chama de engajamento toda e qualquer interação com a postagem ou o perfil. O número de impressões salta aos olhos no período em que foi feita a análise das postagens: cerca de $53 \mathrm{mil}$, em uma média de 5,2 mil por mês. O pico de engajamento acompanha as impressões e as postagens específicas, sobre o dia do Doador de Sangue (25 de novembro, 2019), release Há 25 anos Revista Ciência ¿ Saúde Coletiva subsidia a construção do SUS (27 de março, 2020) e os 40 anos de Alma-Ata (5 de maio, 2020) (Gráficos 2 e 3).

No que se refere ao perfil do público da revista nas redes sociais, a maioria é de mulheres, tanto no Facebook (75\%), com idades entre 25 e 34 anos, e também no Instagram (76\%), com um espectro maior na faixa etária, que vai de 18 a 44 anos. O nível educacional é alto: 33\% dos seguidores das redes declaram ter pós-graduação. Uma porcentagem acima da média no Facebook, levando a concluir que o público das redes sociais é o público-alvo almejado pela revista.

Embora existam desafios, como aumentar o número de usuários e seguidores nas redes sociais, a Ciência \& Saúde Coletiva tem muito a comemorar. Sinto-me honrado em colaborar com o volume 25 , por ocasião do $25^{\circ}$ aniversário. A revista, afinal, recebe anualmente mais de 3.000 artigos originais, dos quais, em média, $20 \%$ são aprovados, evidenciando o rigor das avaliações.

Com temas que reverberam os princípios filosóficos e políticos da Abrasco, a publicação vem subsidiando o debate acerca da implementação das políticas do Sistema Único de Saúde (SUS). Em um ano de pandemia, em que ciência e saúde estiveram no centro do debate na esfera pública, deixo aqui os parabéns ao time que trabalha para manter o alto nível das publicações da revista.

O momento é de olhar para o retrovisor, para reconhecer e validar o caminho percorrido, mas também de voltar os olhos para o futuro, no que diz respeito a seguir se aperfeiçoando e promovendo o acesso livre à informação científica. $\mathrm{O}$ legado dos 25 anos de Ciência \& Saúde Coletiva é de reflexão, qualidade de texto, informação e fomento intelectual. Esse é também o papel da imprensa, que a revista cumpre com louvor. 


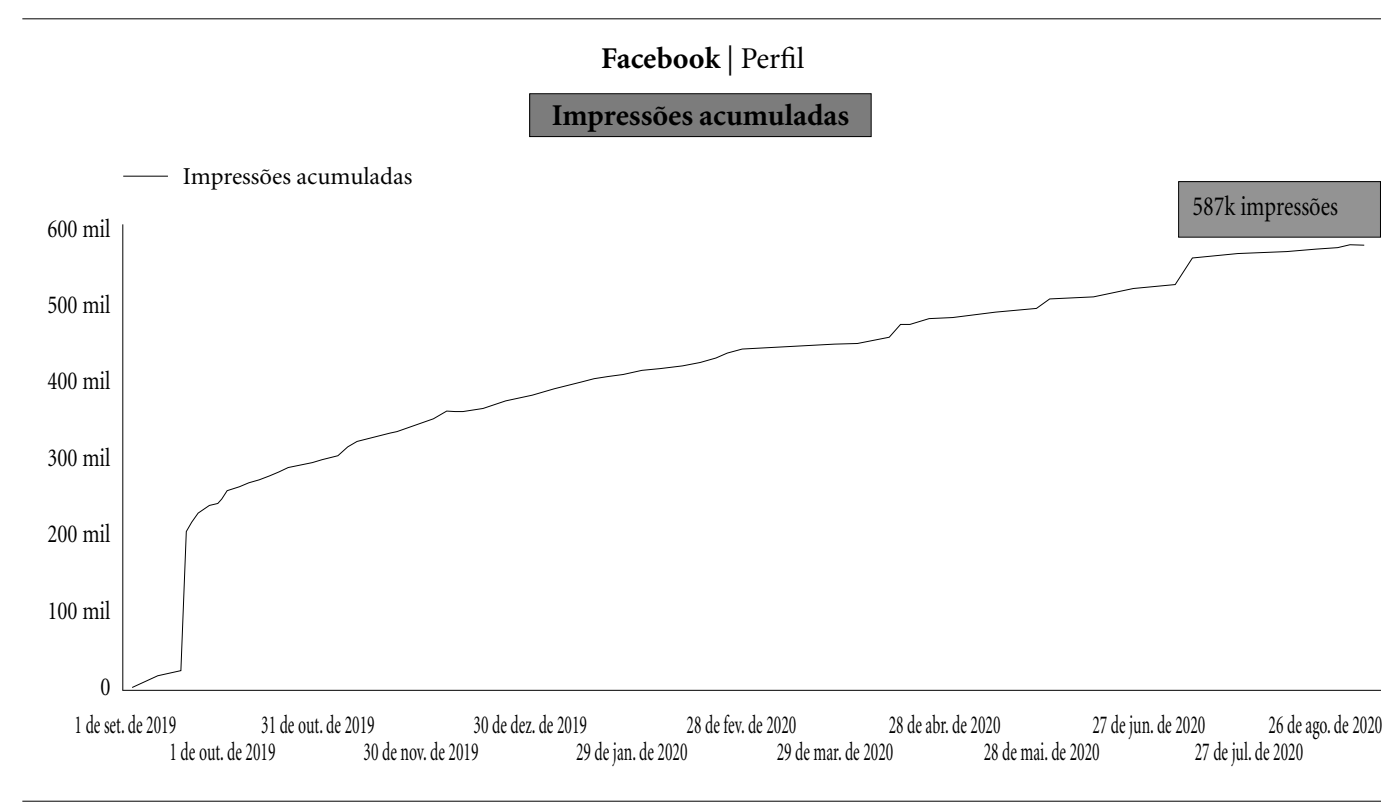

Gráfico 1. Quantidade de impressões do Facebook da Revista Ciência \& Saúde Coletiva.

Fonte: Facebook/revistacienciaesaudecoletiva.

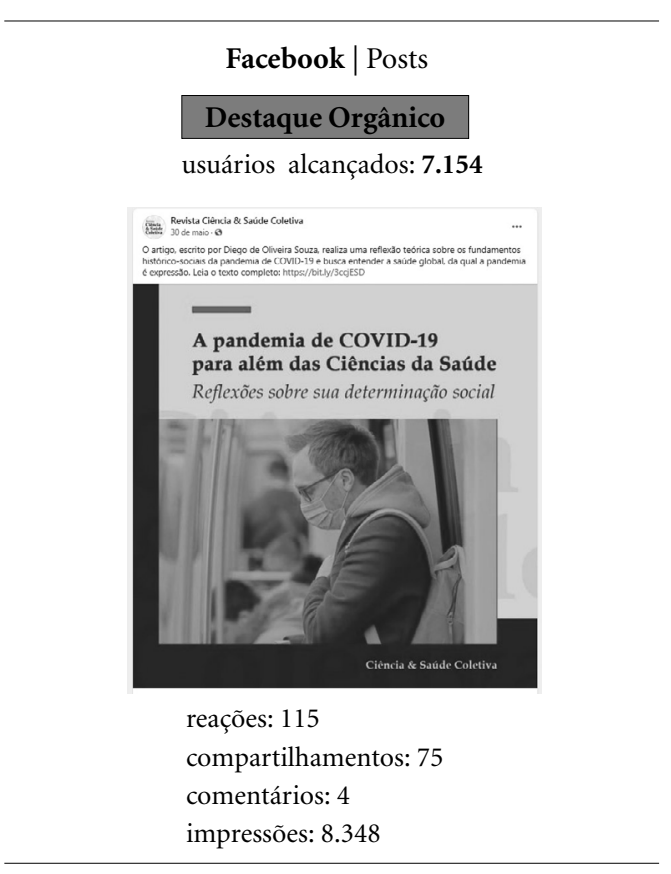

Figura 1. Publicação com maior destaque/alcance orgânico no Facebook da Revista Ciência \& Saúde Coletiva.

Fonte: Facebook/revistacienciaesaudecoletiva.

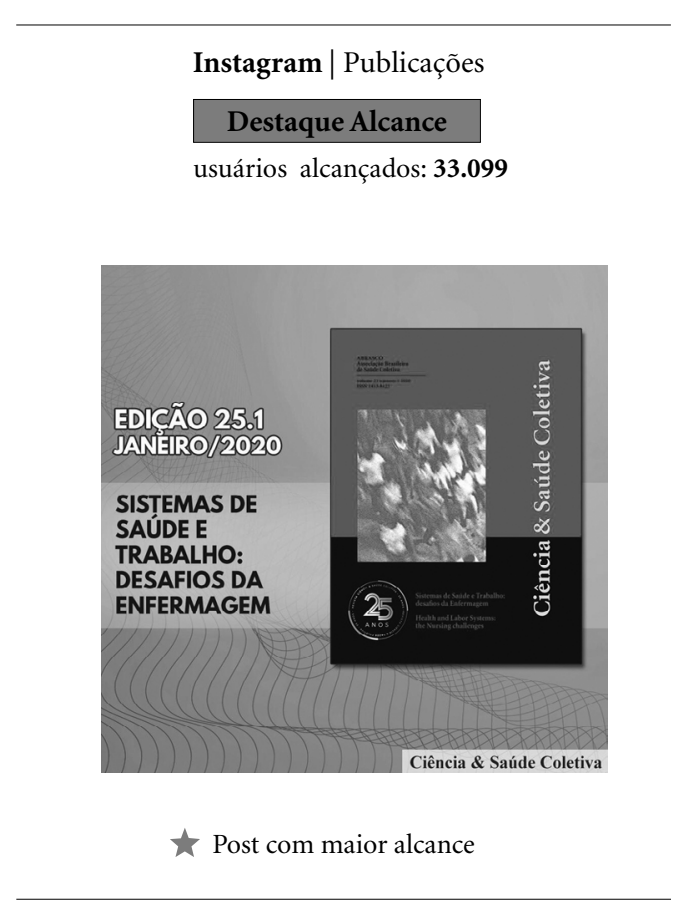

Figura 2. Publicação com maior alcance no Instagram da Revista Ciência \& Saúde Coletiva.

Fonte: Instagram/RevistaCSC. 
Twitter | Perfil

\section{Impressões acumuladas}

Impressões

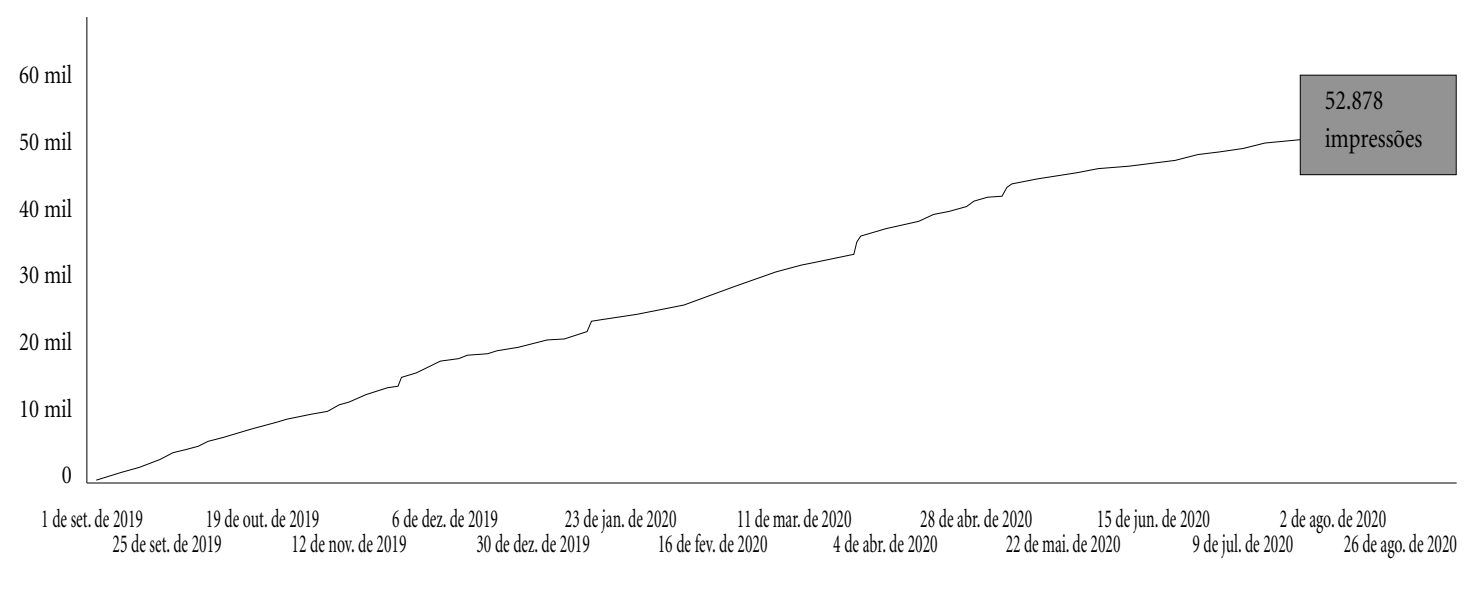

Gráfico 2. Quantidade de impressões acumuladas do Twitter da Revista Ciência \& Saúde Coletiva.

Fonte: Twitter@revistacienciaesaudecoletiva.

Twitter | Perfil e Posts

Melhores picos de impressão

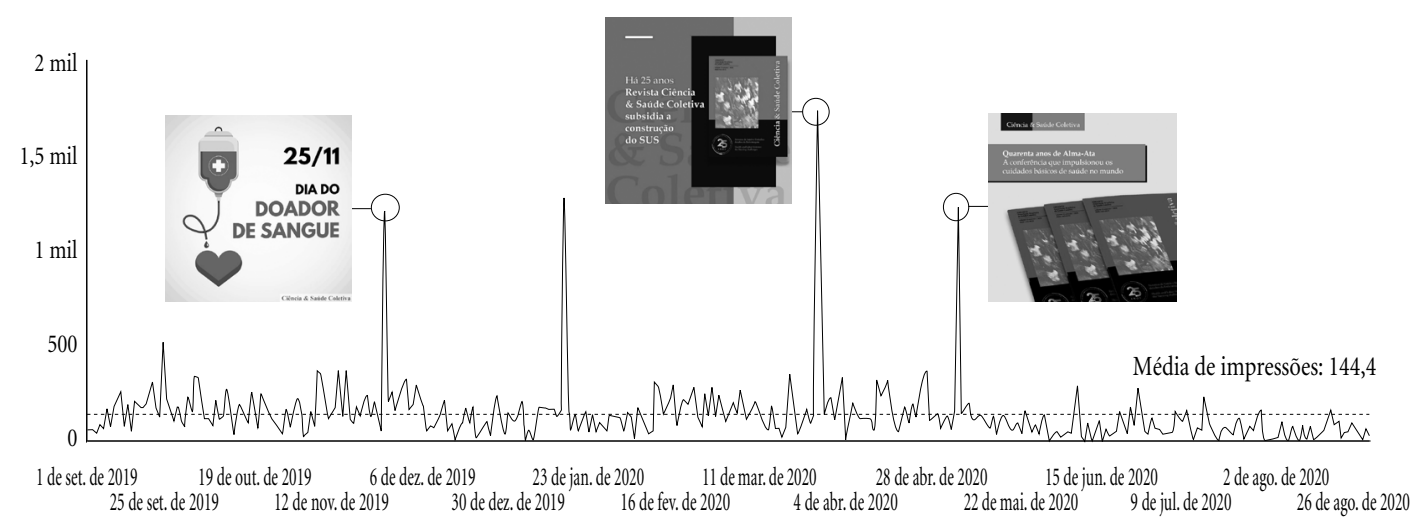

Gráfico 3. Postagens que tiveram melhores picos de impressão no Twitter da Revista Ciência \& Saúde Coletiva.

Fonte: Twitter@revistacienciaesaudecoletiva. 


\section{Referências}

1. Packer AL. Indicadores de centralidade nacional da pesquisa comunicada pelos periódicos de Saúde Coletiva editados no Brasil. Cien Saude Colet 2015; 20(7):1983-1995.

2. Google Scholar. Principais publicações - Saúde/Brasil [Internet]. [acessado 2020 Out 11]. Disponível em: https://scholar.google.com/citations?view_op=top_ venues\&hl=pt-BR\&vq=pt

3. Web of Science Group. Clarivate Analytics. Research Excellence Awards Brazil 2019 [Internet]. [acessado 2020 Out 11]. Disponível em: https://discover. clarivate.com/Research_Excellence_Awards_Brazil_ Download

4. Minayo MCS, Gomes R, Silva AAM. Vitória da Revista Ciência \& Saúde Coletiva da Abrasco. Cien Saude Colet 2019; 24(9):3176-3177.

5. Galhardi CP, Freire NP, Minayo MCS, Fagundes MCM. Fato ou Fake? Uma análise da desinformação frente à pandemia da Covid-19 no Brasil. Cien Saude Colet 2020; 25(Supl. 2):4201-4210.

Artigo apresentado em 12/10/2020

Aprovado em 13/10/2020

Versão final apresentada em 15/10/2020 